\title{
Methods of Traffic Demand Forecast on Tourism Highway
}

\author{
Zhenguo Liu ${ }^{1, a^{*}}$, Xianguang Wang ${ }^{2, b}$ and Shiyu Shen ${ }^{3, c}$ \\ ${ }^{1}$ China Academy of Transportation Sciences, Beijing, China \\ ${ }^{2}$ China Academy of Transportation Sciences, Beijing, China \\ ${ }^{3}$ China Academy of Transportation Sciences, Beijing, China

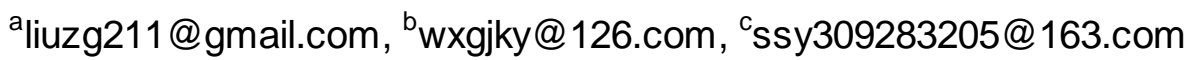

\section{Keywords: Tourism highway, Four-step Model, Background traffic volume}

Abstract. Tourism traffic forecast is the foundation for the planning and construction of tourism highway and supporting facilities. By analyzing the characteristics of tourism traffic, we divided the tourism traffic into two parts: tourism traffic and background traffic. For tourism traffic forecast, we need to consider the characteristics of the tourism trips, tourism attraction capacity and tourism impedance as important factors. On this basis, we improved the Four-steps Method containing traffic generation, trip distribution, modal split and traffic assignment in the network, and computed the traffic volume of tourism highway. Conventional method of traffic demand forecast is used to calculate the background traffic volume. All traffic volume on tourism highway is composed of tourism traffic volume and background traffic volume.

\section{Introduction}

Tourism traffic is an indispensable part of tourism activities and a prerequisite for the emergence and development of tourism industry.

Along with the economic development and social progress, the volume of tourism trips grew rapidly. The structure of traffic demands primarily induced by commuter trips will gradually change, and the proportion of the traffic demands induced by recreational and casual trips will increase in the future.

Although tourism traffic conditions, in recent years, has been continuously improving. A series of tourism traffic infrastructure has been planned and constructed. However, the incompetence of demand and supply of tourism traffic is still serious. Problems such as traffic congestion, poor transportation structure, and defective road network are still affecting the development of tourism industry.

Traffic demand forecast lays the foundation for pre-planning of transportation projects. A new issue in this area studied by both traffic and tourism industry in recent years is the traffic demand forecast of highway tourism, which is significant for tourism planning and traffic planning. More and more attention has been paid to improve the quality of traffic demand forecast of highway tourism, especially in nowadays when tourism planning and traffic planning are having more in-depth integration. Therefore, it is of great significance to discuss the features of tourism trips and analyze the methods of traffic demand forecast of highway tourism.

\section{Traffic demand characteristics of tourism highway}

Tourism highway is designed for accessing and connecting scenic regions and tourism attractions, providing infrastructure for tourism vehicles and pedestrians. Compared to general highway or urban highway, the difference is that the major function of tourism highway is serving tourists, with characteristics of poor accessibility, long tourism routes, scattered distribution, and large seasonal variation. In addition, the functional difference also leads to different traffic demands.

Particularity of the service objects of tourism highway. The difference of tourism highway compared to general highway is that the major function of tourism highway is serving tourists. The service objects of tourism highway network are tourists, while the service objective of general highway is providing favor-able travel environment for the users. According to the time, destination and origin of tourism trips, the service objects of 
tourism highway can be categorized into two types: suburban area trips and tourism attraction trips. The surrounding cities originate the trips of weekend suburban tourists, with characteristics of short distance, short time, low price and strong randomness, therefore the traffic demands of which have relatively large dynamic fluctuation. While the scenic attraction trips usually have long travel time, mainly composed of team and business tours, complemented by free tours.

Time characteristics of the traffic volume on tourism highway. In the long term, the traffic volume of typical tour-ism highway has obvious seasonal variation and dis-continuity, namely intermittent traffic volume. Traffic flow of tourism highway with moderate and low traffic volume, especially in the north area, has evident seasonal variations. During peak tourism sea-sons, the traffic volume will have considerable in-crease. In view of this characteristics, each tourism region has its own corresponding high season and off season. Moreover, the traffic volume of tourism highway is also different from that of general high-way regarding to morning peak and evening peak during everyday trips.

Interaction between tourism transportation and local economics. In consequence of the financial situation in some tourism area is at a less developed level, more convenient transportation is required to promote local economic development. Regarding to central mountainous areas, construction of tourism highway can accelerate the development of local tourism and related industries, and further promote the increase of tourism traffic volume. Hence, the economic growth brought by highway construction should be high-lighted in traffic demand forecast, which mainly re-lies on future economic growth indicators, not cur-rent economic status.

Tourism highway need more favorable service facilities. In order to take full advantage of tourism highway function, the configuration, quality and level of service of the service facilities on tourism highway would be more demanding. The major service facilities of tourism highway include traffic safety facilities, highway signs and interpretation systems, highway service facilities and highway connection systems, etc. Vehicles on tourism highway composed primarily of passenger cars, which have lighter axle load, more compact cars, less heavy vehicles, more passengers and less freight. Additionally, lots of tourism highway have lower class, poor vehicle condition and insufficient sense of safety, posing serious pressures to the tourists. Traffic accidents happen frequently on those tourism highway, creating negative effects on the society. Moreover, the great majority of the tourists came from other places, not familiar with local highway condition, which brings higher requirements for the level of service of tour-ism highway, especially safety.

Environmental landscape puts higher requirements for tourism highway. The purposes of tourist trips are extremely varied. Tourism highway should not only meet the basic traffic demand of delivering the tourists, but also provide them with a pleasing appearance and beautiful environment, satisfying and comforting them during the whole trip. On the premise of safety, the alignment of tourism highway should take consideration of aesthetics, the traffic characteristics and construction techniques of tourism highway should satisfy both the physiological and psychological needs of the tourists, avoiding monotonic and tedious driving section in the alignment. In addition, the construction of tourism highway should start from the angle of environmental protection, proposing construction measures regarding environmental protection, protecting the surrounding environment, reducing environmental pollution, implementing energy saving and emission reduction measures, corresponding to the policy of "Green Transportation" and "Wild China".

\section{Idea of traffic demand forecast on tourism highway}

The same as general highway, the traffic volume of tourism highway also consists of three parts: trend traffic volume, induced traffic volume and diverted traffic volume. However, there are big differences between the forecast method and influential factors. First of all, tourist volume is the subset of integrated traffic volume and highway passenger volume. Second, if applying the conventional forecasting process, namely integrated traffic volume - highway passenger volume - highway tourist passenger volume or integrated passenger traffic volume - integrated passenger traffic volume - highway tourist passenger volume, the workload would be 
considerably heavy. Third, the seasonal variation of tourist passenger volume is highly evident, thus it is of slight significance to forecast the average passenger volume.

There are huge differences between traffic demands of tourist trips and daily trips, especially on travel distances and time. It is not only related to the planning region, but also bounded up with the wide origins of tourists. In addition, tourist passenger volume has large seasonal fluctuation, distinct time and economy characteristics. Therefore, for traffic demand forecast of tourism traffic, it is difficult to di-vide the region into traffic zones, and is not applicable to use the conventional gravity model. The idea of this paper is to forecast the tourism traffic volume and background traffic volume separately. For tour-ism traffic volume, the tourist demand could be forecasted, based on tourism impedance of the tour-ism region, by analyzing origins of the passengers, and the tourism traffic demand could be forecasted on the basis of structure of the trips. While the back-ground traffic volume can be obtained by applying the regular forecasting method.

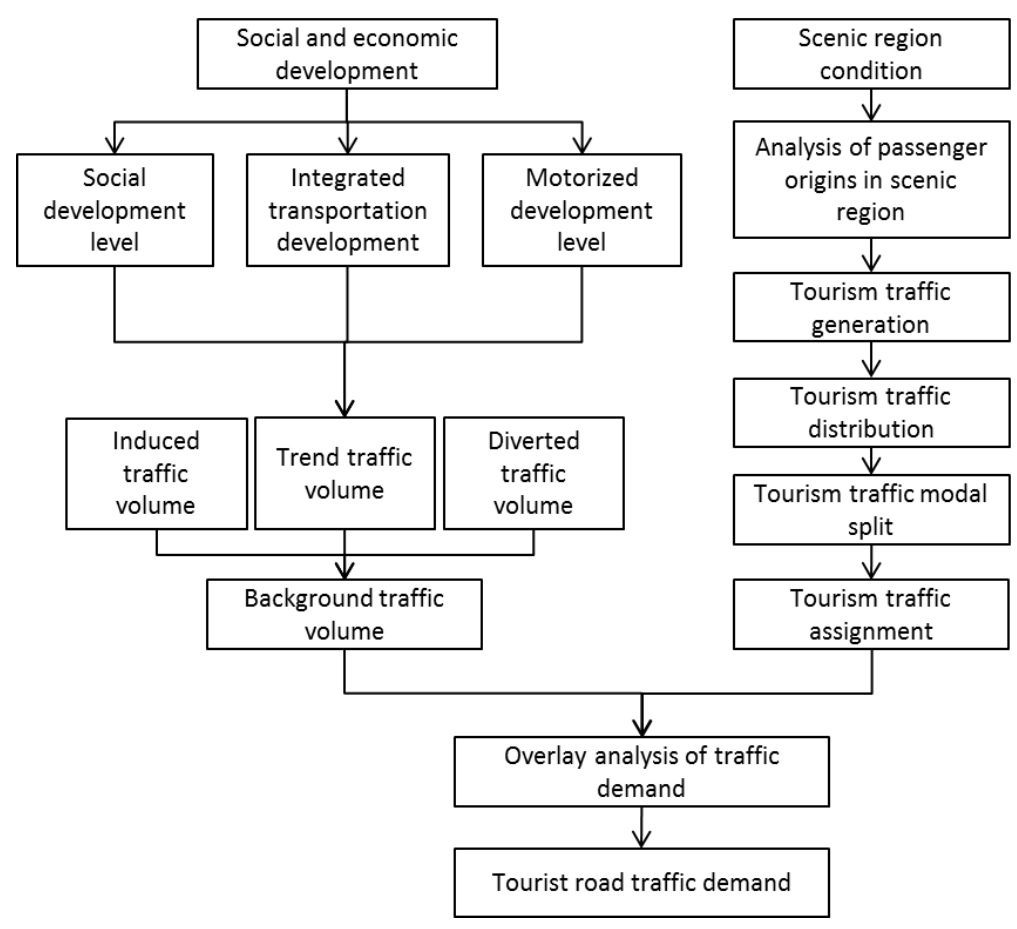

Figure 1. Technical route of traffic demand forecast for tourism highway

\section{Tourism traffic volume forecast}

Traffic generation forecast. Traffic generation forecast contains production fore-cast and attraction forecast. Methods mainly applied include production rate method and capacity restraint method. New scenic regions generally use production rate method while existing scenic regions generally use capacity restraint method. For existing scenic regions, the historical statistics of the number of tourist receptions could be used, while for new scenic regions, the planning number of tourist receptions would be used as basic data for the future forecast. Frequently used method include average growth rate method, time series method, correlation method, elasticity coefficient method, plus combined forecasting model. Exploitation level of the scenic regions varies, thus the number of tourist receptions in similar scenic regions can also be used in the forecast, verified by the capacity of the original scenic region.

The arrival and departure of the tourists generate two traffic trips, but the number of tourists only count for once. Hence the number of tourists should be doubled when converted to the tourism traffic volume. In addition, the tourism traffic generation shows obvious seasonal variation, the tourism traffic volume in different time period during high season and off season differs apparently. In tourism traffic generation forecast, specific 
attention should be paid to set up a time frame adjustment parameter, in order to improve the accuracy of the forecast.

Traffic distribution forecast. Average growth rate method and gravity model method are generally used in tourism traffic distribution forecast. This paper mainly introduces the latter one. The basic assumption of gravity model is: the tourism traffic distribution from zone $i$ to zone $j$ is proportional to the traffic generation of zone $i$ and traffic attraction of zone $j$, and inversely proportional to the tourism traffic impedance between zone $\mathrm{i}$ and zone j. It is essential to analyze the importance of each scenic region, quality of the tourism resources, and impacts of the traffic accessibility.

$$
X i j=\text { Ti Uif }(t i j) / \sum U j f(t i j)
$$

In Eq. 1:

Xij- tourism traffic distribution from zone $\mathrm{i}$ to zone $\mathrm{j}$,

Ti- traffic generation of zone $i$,

Uj- traffic attraction of zone $\mathrm{j}$,

Tij- tourism traffic impedance between zone $\mathrm{i}$ and zone $\mathrm{j}$,

f(tij)-traffic impedance parameter.

Traffic modal split. The transportation organization method of tourism highway varies greatly, which can be primarily categorized into three manners: the first one is tourist coach, mainly served for team tourists, which is the basic method of highway tourist traffic; the second one is tourist shuttle bus, which is used to satisfy the individual tourist; the third one is private car. Team tourists coaches still are the main forces in tourist passenger transportation, but the latter two methods, due to the rapid development of national public transportation and the publication of Free Tolls for Small Passenger Cars on Major Holidays, should not be underestimated. Statistical models, such as Probit model and Logit model, are generally used in traffic modal split.

According to investigate the average seats by vehicle type, load factor and vehicle type proportion, the tourism traffic volume can be converted into standard PCU passenger car traffic volume based on the conversion factor of different car types.

Traffic volume assignment. Tourism traffic network assignment plays an important role in tourism traffic planning. The primary methods used in tourism traffic network assignment include capacity restraint — incremental load assignment and capacity restraint — equilibrium iteration, which could be realized by iterative computation after establishing the GIS highway network in the computer. In addition, tourism traffic flow is different from other general social traffic flow, which has particularity in vehicle route, speed limit and traffic control measures. Thus, logical control rules should be added in establishing the assignment network.

\section{Background traffic volume forecast}

Background traffic volume consists of three parts: trend traffic volume, diverted traffic volume and induced traffic volume.

Trend traffic volume indicates the traffic volume formed by the natural increase, according to its inherent laws, of the current traffic volume, which is generally forecasted based on the condition of social and economic development. After the construction of highway projects, major changes are most likely to occur in the layout and structure of existing transportation network, as well as the operational indicators and parameters, which would cause traffic volume diversion between other transportation modes and the projects. In general, diverted traffic volume is forecasted by applying expert consultation method.

According to the mechanism of traffic generation, induced traffic volume can be divided into induced traffic volume based on travel conditions and induced traffic volume based on economics. Induced traffic volume 
based on travel conditions indicates the potential traffic volume induced by the improvement of travel condition and level of service in the area of influence after the new construction or reconstruction of the highway. Induced traffic volume based on economics indicates the traffic volume induced by the improvement of network structure, which affects the industrial distribution and regional economics and changes the land utilization around the highway.

\section{Summary}

This paper, starting from typical highway traffic demand, analyzed the characteristics of tourism high-way traffic and improved the conventional tourism traffic demand forecast methods. It proposed Four-step Method in tourism traffic demand forecast combined with social and economic develop model and characteristics of tourism traffic demand development, plus the forecast method incorporated with background traffic volume and tourism traffic volume. The accuracy of the tourism traffic volume forecast could contribute to the allocation of vehicles and vehicle types, therefore providing better service with the tourists.

\section{References}

[1] Ping Huang. Highway Tourism Passenger Traffic Volume Forecast. Journal of Chongqing Jiaotong University, 2002, 21(4) 51-53.

[2] Hongzhi Guan, Jun Ren, Lanhui Liu. The Basic Framework of Tourism Traffic Planning. Beijing City Planning \& Con-struction Review, 2001, (6)32-35.

[3] Wenbin Zhang, Bo Wang, Xianyi Chen. Study of Tourism Traffic Volume Forecast Model, 2013, 4, 87-90.

[4] Jifeng Dai, Huapu Lu, Zhonghua Tang. Study of Analysis Method of Traffic Impacts on Tourism Projects. Journal of Highway and Transportation Research and Development, 2003, 20(4): 67-70, 79.

[5] Wei Wang, Xiucheng Guo. Traffic Engineering. Nanjing: Publishing House of Southeast University, 2000 .

[6] Bihu Wu. Principle of Regional Tourism Planning. Beijing: China Tourism Publishing House, 2001. 